\title{
Light and Scanning Electron Microscopic Study on the Tongue and Lingual Papillae of the Japanese badgers, Meles meles anakuma
}

\author{
By \\ Ken YOSHIMURA ${ }^{1}$, Junji SHINDO ${ }^{2}$ and Ikuo KAGEYAMA ${ }^{1}$ \\ ${ }^{1}$ Department of Anatomy, Faculty of Life Dentistry, The Nippon Dental University at Niigata, Niigata, JAPAN \\ ${ }^{2}$ Laboratory of Wildlife Science, Dept. of Environmental Bioscience, School of Veterinary Medicine, Kitasato University, \\ Towada, JAPAN
}

- Received for Publication, September 29, $2008-$

\begin{abstract}
Key Words: Badgers, Mustelidae, lingual papillae, comparative anatomy, scanning electron microscopy
Summary: We observed the three-dimensional structures of the external surface and connective tissue cores (CTCs), after exfoliation of the epithelium of the lingual papillae (filiform, fungiform and foliate papillae) of the Japanese badgers (Meles meles anakuma) using scanning electron microscopy and conventional light microscopy. Macroscopically, the tongue was elongated anterior-posteriorly and the apex rounded. Numerous filiform papillae and fungiform papillae were distributed all over the tongue except at the root. Seven vallate papillae were observed that had circumferential furrows and were arranged in V-shape. Numerous taste buds were observable in the furrows. Instead of foliate papillae, a lateral organ lacking taste buds was present on the lateral edge of the posterior tongue. Behind the vallate papillae, dome-like lingual tonsils that had globular tonsils were densely distributed in $\mathrm{U}$-shaped arrangement. Rather long conical papillae were distributed around the vallate papillae. At the posterior end of the root of the tongue, lingual papillae were very much attenuated and only fold-like structure was seen. CTCs of filiform papillae had a main rod-like slender core and ovally arranged short accessory cores distributed around the main core. CTCs of fungiform papillae exhibited a columnar like appearance. The lingual papillae of Japanese badger's tongue fundamentally had morphological similarity with carnivore species, included the Pinnipedia.
\end{abstract}

There have been many comparative morphological studies of mammal species that revealed mammals have characteristic variations in regards to the tongue and distribution of the different types of lingual papillae due to their dietary habits; (carnivorous, omnivorous and herbivorous, and their living environment. In particular regarding the lingual papillae, there are many threedimensional structural differences of the lingual papillae and their connective tissue cores (CTCs) after removal of the overlying epithelium (Kobayashi et al., 1988, 1989, 1992).

Among mammalian families, Mustelidae are widely distributed living representatives in all continents except Antarctica and Australia. At the same time, these species are regarded as the smallest carnivore. This family also contains amphibious (semi-aquatic) members (Macdonald, 1984).

Some morphological observations have been reported about the lingual papilla of Mustelidae: Mustela sibirica coreana (Siberian weasel), Mustela putorius furo (Ferrett): Emura et al. (2008), Martes melampus melampus (Japanese Marten): Emura et al. (2007) and Enhydra Lutris (Sea Otter): Shimoda et al. (1996).

However, information in the literature regarding the structure of the lingual mucosa of the Mustelidae species, badgers was absent. The Japanese badger (Meles meles anakuma), a medium-sized carnivore that is a subspecies of the Eurasian badger (Meles meles meles), inhabits Honshu, Kyushu, Shikoku, and Shodoshima in Japan (Tanaka, 2005). We assumed that the morphological features of the lingual papillae of Japanese badgers would possess some morphological differences originating from the adaptation to their dietary habits and/or living environment.

The aim of this study was to investigate in detail both three-dimensional structures on the surface of the lingual papillae and their CTCs after exfoliation of the epithelium on the dorsal surface of tongue of Japanese badger. 


\section{Materials and Methods}

\section{Tissue specimens and preparation}

Two Japanese badgers (Meles meles anakuma) (Body length: Male; $72 \mathrm{~cm}$, Female; $77 \mathrm{~cm}$, Body weight: Male; $3.8 \mathrm{~kg}$, Female; $4.7 \mathrm{~kg}$ ) with tongues (average length between apex and most posterior position: Male; $7.0 \mathrm{~cm}$, Female; $7.5 \mathrm{~cm}$; width at the broadest part of the tongue: Male; $2.3 \mathrm{~cm}$, Female; $2.6 \mathrm{~cm}$ ) that died subsequent to traffic accidents were used for this study. Specimens were fixed with $10 \%$ formalin for postmortem autopsy. Shortly after that, blocks were then cut from various parts of the tongue.

\section{Light microscopy}

For light microscopy, specimens were dehydrated with a graded series of alcohol. Following dehydration, specimens were embedded with paraffin and sectioned four micrometers thick. Sections were stained with hematoxylin-eosin (H-E). These slides were observed with a light-field light microscope (BH-2, Olympus, Japan).

\section{Scanning Electron Microscopy}

For scanning electron microscopy, specimens were immersed with $3.5 \mathrm{~N}-\mathrm{HCl}$ for 2 weeks at room temperature $\left(25-28^{\circ} \mathrm{C}\right)$. After immersion of the specimens, the epithelium was exfoliated from the underlying CTCs at the boundary of epithelium-connective tissue layer. Specimens were washed with tap water, and then treated with a $0.5 \%$ tannic acid solution. Post fixation was accomplished by a ten-minute immersion in a $1 \% \mathrm{OsO}_{4}$ solution. Specimens were then washed and dehydrated with a graded series of ethanol.

After dehydration, specimens were freeze-dried with a t-butyl alcohol freeze-drying method (Inoue and Osatake, 1988). Before observation, specimens were coated with $\mathrm{Pt}-\mathrm{Pd}$, and then observed with a scanning electron microscope (S-800, Hitachi-Hi-Technologies, Japan).

\section{Results}

\section{1) Macroscopic Overview}

In the macroscopic images, the tongue of the Japanese Badger (Fig. 1) appears elongated anterior-posteriorly and its apex was rounded. Numerous filiform papillae and fungiform papillae were distributed along the entire tongue except at the root. Seven vallate papillae (Fig. 1b; VP) were arranged in a V-shape. Foliate papillae however were absent. Instead of foliate papillae, a lateral organ (Fig. 1b; Lat) that is often seen in carnivores existed on the lateral edge of the posterior tongue. Behind the vallate papillae, dome-like lingual tonsils (Fig. 1b; LT) were densely distributed in U-shaped arrangement. Rather long conical papillae were distributed around vallate papillae (Fig. 1b; CP). At the posterior end of the root of
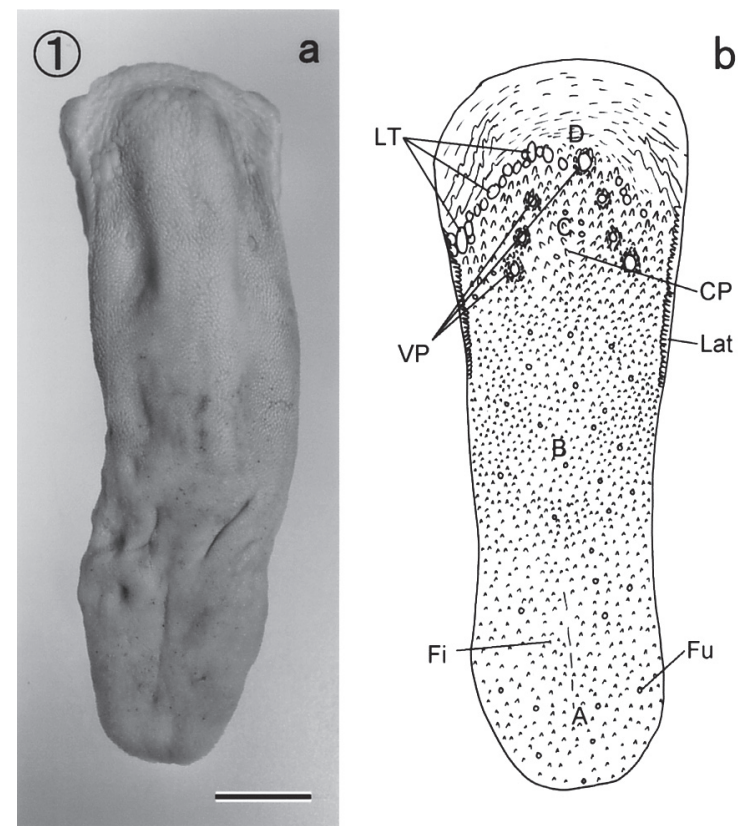

Fig. 1. a: Overview of the dorsal surface of the tongue of the Japanese Badger (Meles meles anakuma). Scale bar $=1 \mathrm{~cm}, \mathrm{~b}$ : Diagram of the tongue; A: Anterior part, B: Middle part, C: Posterior part. D: Root. Fu: Fungiform papilla, Fi: Filiform papilla, Lat: Lateral organ, CP: Conical papilla, VP: Vallate papilla, LT: Lingual tonsils.

the tongue, lingual papillae were very much attenuated and only fold-like structures were observed.

\section{2) Microscopic Observation a) Filiform Papillae}

Lightmicroscopy revealed that the epithelium (Fig. 2d) exhibited rather weak keratinization with a cornified layer that had nuclei in the most superficial cells. Keratohyaline granules were not observable. No lingual glands were observable in the lamina propria of the anterior and middle part of the tongues.

Under scanning electron microscopy, the external appearance of the filiform papillae, which were distributed on the apical part of the tongue, was a rather thick conical shape (Fig. 2e) withs several studded accessory protrusions. These filiform papillae were inclined towards the posterior direction. Thicknesses of the filiform papillae were varied depending on the area. Filiform papillae that were distributed in the middle (Fig. 1b; B) appeared to be somewhat elongated and accessory protrusions were attenuated (Fig. 3a). After exfoliation of the epithelium, CTCs of each filiform papilla had a main rod-like slender core and ovally arranged (10 or more) short accessory protrusions distributed around the main core (Fig. 2f). The main cores of filiform CTCs that were distributed in the middle 

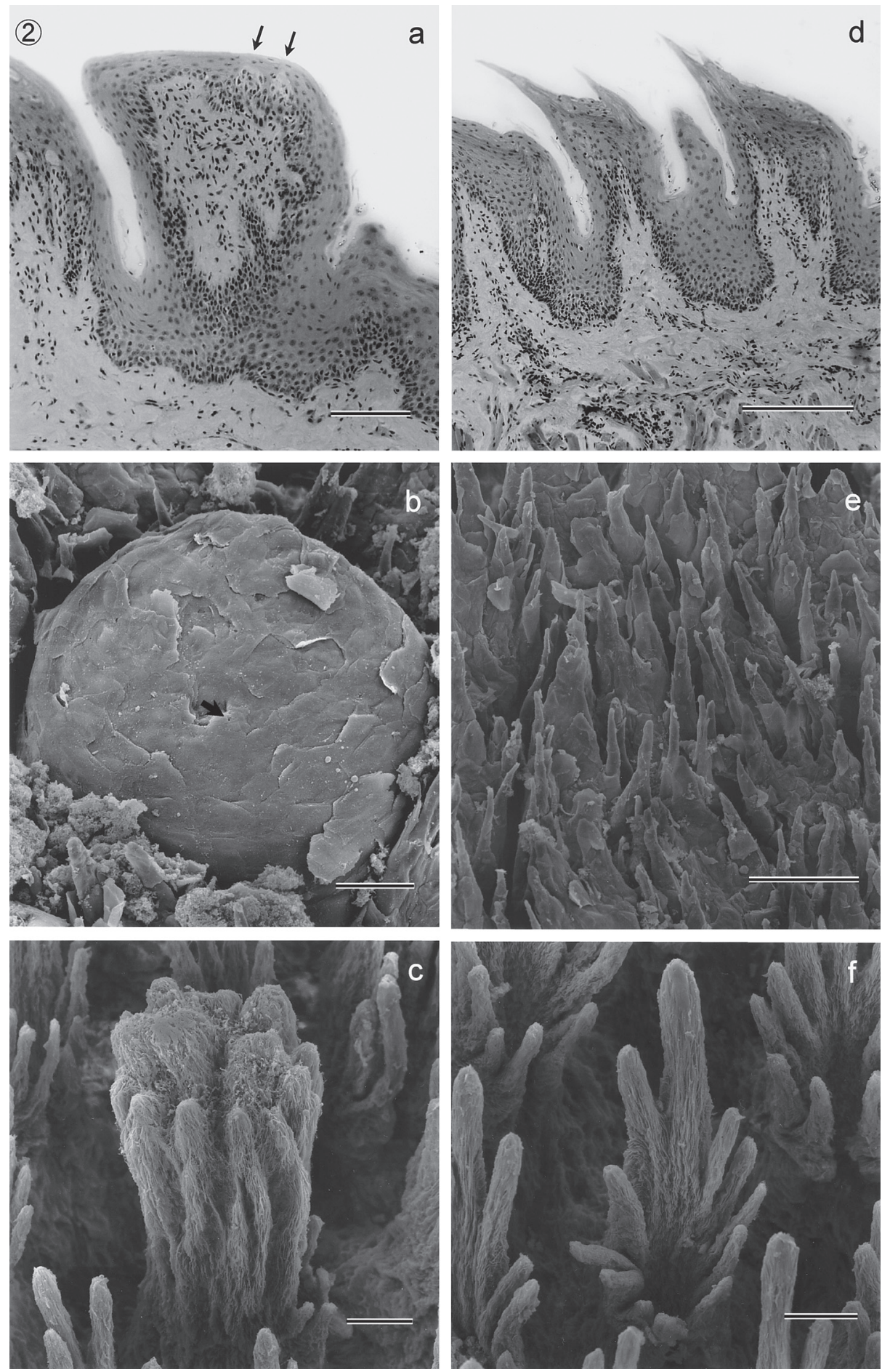

Fig. 2. A set of lingual papillae distributed on the anterior part of the tongue. a: Light micrograph of fungiform papillae distributed on the apex of tongue (sagittal section). Taste buds (indicated with arrows) were seen on the top of the papilla. Scale bar $=100 \mu \mathrm{m}$. b: Scanning electron micrograph of the external surface of fungiform papilla distributed on the apical part of tongue. Taste pore (arrow) was observable. Scale bar $=50 \mu \mathrm{m}$. c: SEM micrograph (after epithelium exfoliated) of the connective tissue core (CTC) of a fungiform papilla on the apical part of tongue. Columnar-like CTC was observable after removal of the epithelium. Scale bar $=50 \mu \mathrm{m}$. d: Light micrograph of filiform papillae distributed on the apical part (sagittal section). Some nuclei were observable also on the stratum corneum. Scale bar $=200 \mu \mathrm{m}$. e: SEM micrograph of the apical part of tongue showing the epithelial surface of filiform papillae. Rather thick conical protrusions of filiform papillae were inclined toward the posterior direction. Accessory protrusions were distributed on the main protrusions. Scale bar $=100 \mu \mathrm{m}$. f: CTCs of the filiform papillae distributed on the apical part of the tongue after removal of the epithelium. A main rod-like slender core was observable. Ovally arranged short accessory cores were seen around the main core. Scale bar $=50 \mu \mathrm{m}$. 

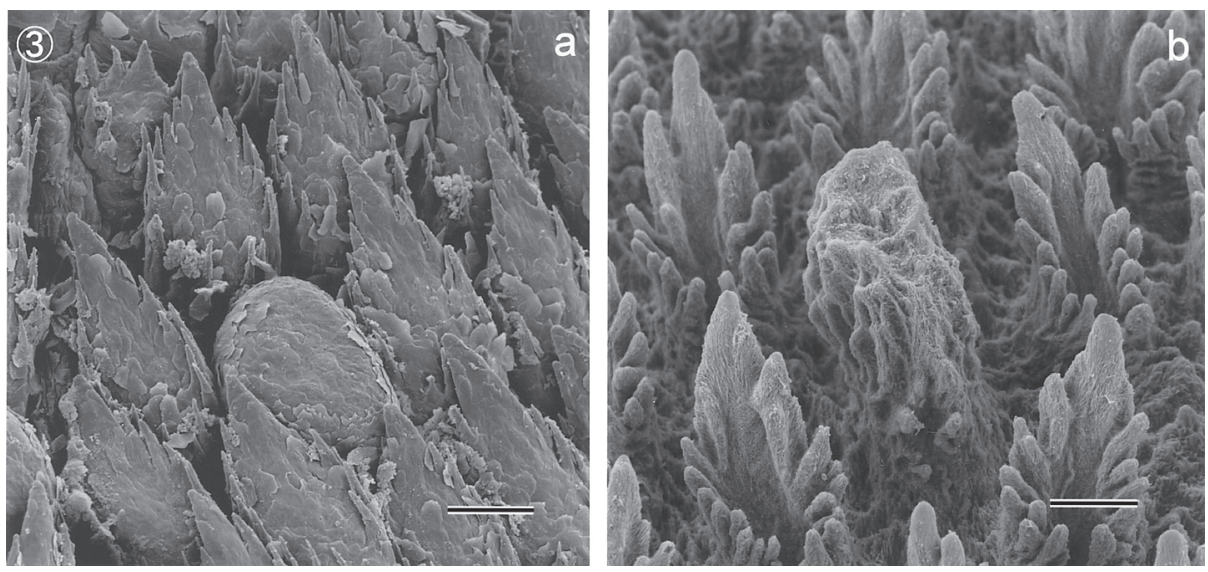

Fig. 3. A set of filiform and fungiform papillae distributed on the middle part of the tongue (indicated as "B" on the Fig. 1b). a: SEM micrograph of the epithelial surface of filiform and fungiform papillae. Appearance of the filiform papillae distributed in this area was comparatively elongated and accessory protrusions were attenuated. Scale bar $=150 \mu \mathrm{m}$. b: SEM micrograph of the CTCs of the filiform and fungiform papillae after removal of the epithelium. The main cores of filiform CTCs in this area exhibited a somewhat robust conical appearance. Some of the fungiform CTCs in this area were somewhat larger compared to fungiform CTCs distributed on the apical part. Scale bar $=100$ $\mu \mathrm{m}$.

part pf the tongue (Fig. 1b; B) exhibited a somewhat robust conical appearance (Fig. 3b). The filiform papillae were approximately $210-500 \mu \mathrm{m}$ long and 140 $260 \mu \mathrm{m}$ wide.

\section{b) Fungiform Papillae}

Under lightmicroscopy, the top of the fungiform papilla (Fig. 2a) was dome-like. Keratinization of these fungiform papillae was also weak and some nuclei of epithelial cells remained in the most superficial cells. A few taste buds were observable in the epithelium of the fungiform top.

In SEM observations, the external surface of fungiform papillae distributed on the anterior part of tongue (Fig. 2b) was smooth and dome-like, however their size was variable. After epithelial exfoliation, CTCs of fungiform papillae on the apical part of tongue (Fig. 2c) were columnar-like. The fungiform papillae were approximately $240-360 \mu \mathrm{m}$ in diameter.

\section{c) Lateral organ}

Under lightmicroscopy, the external appearance of the lateral organ was spine-like. Taste bud-like structures were not observable and salivary glands did not exist in the lamina propria.

SEM observations revealed that spine-like protrusions inclined toward midline were arranged in a row along the lateral edge of the tongue and appeared serrated (Fig. 4b). After exfoliation of the epithelium of lateral organ, large cone or columnar-like CTCs were seen. Numerous small protrusions were distributed from the lateral side of the each CTC (Fig. 4c).

\section{d) Vallate papillae}

On the dorsal surface of the lingual mucosa of Japanese badgers tongues, seven vallate papillae were arranged in a V-shape. Lightmicroscopy, revealed numerous taste buds in the circumferential groove. Von Ebner glands were seen in the lamina propria (Fig. 5a) and their orifices opened into the circumferential groove.

In SEM observations, the external surface of vallate papillae consisted of a dome-like papilla and a surrounding circumferential groove and furrow. After exfoliation of the epithelium, CTCs of vallate papillae were covered with small protrusions. CTCs in the circumferential furrow were covered with small protrusions. Vallate papillae were approximately $660-1260$ $\mu \mathrm{m}$ in diameter.

\section{e) Dome-like lingual tonsils}

Under lightmicroscopy, tonsils were observable on the superficial part of the lamina propria. Tonsillar follicle-like structure was observable however no crypts were found. Mucous-rich mixed salivary glands were situated in the deep part of the lamina propria.

Numerous dome-like globular tonsils were distributed in this area. After removal of the epithelium, SEM observations revealed that lymphoid tissue seemed to be mounted on the stem-like CTCs. Surrounding ridge-like CTCs that had numerous small protrusions was also seen. Lingual tonsils were approximately 680 $-2540 \mu \mathrm{m}$ in diameter.

\section{f) Conical Papillae}

Lightmicroscopy, revealed rather sharp conical papillae distributed on the posterior part of the tongue. Keratinization of the large conical papillae was not high and nuclei were seen on the stratum corneum. Large mixed salivary glands were distributed in the lamina propria beneath this area. 

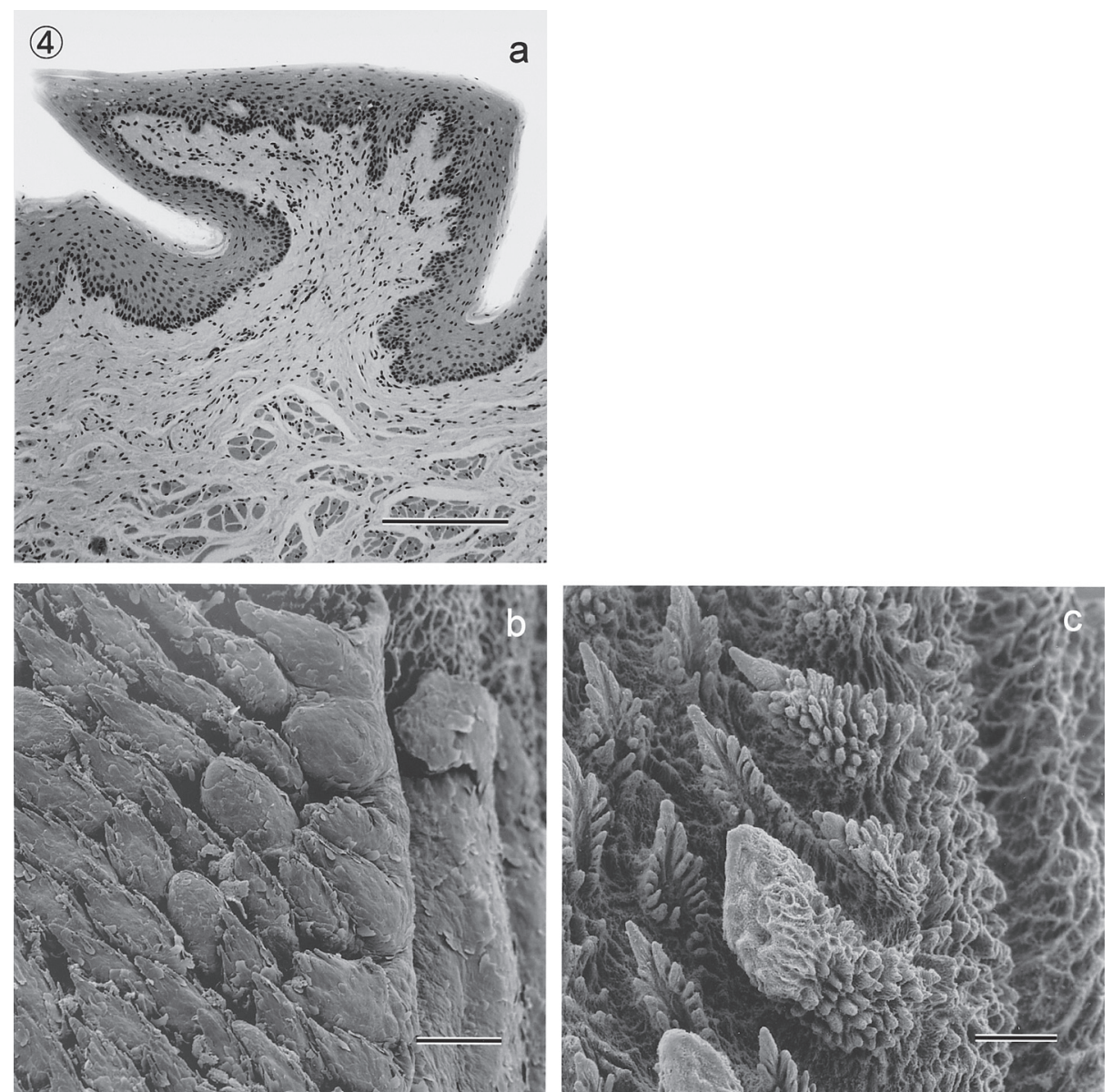

Fig. 4. A set of lateral organs distributed on the lateral edge of the middle-posterior part (indicated as "Lat" on Fig. 1b). a: Lightmicrograph of a lateral organ (frontal section). Taste bud-like structures were not observable. Scale bar $=500 \mu \mathrm{m}$. b: SEM micrograph of the epithelial surface of the lateral edge of the middle-posterior part of the tongue. Numerous spine-like large conical lateral organs were arranged in a row along the lateral edge of the tongue. These conical lateral organs were inclined towards the midline. Scale bar $=300 \mu \mathrm{m}$. c: SEM micrograph of the CTCs of the lateral organ after removal of the epithelium. Large cone or columnar-like CTCs were seen. Numerous small protrusions were distributed from lateral side of the each CTCs. Scale bar $=200 \mu \mathrm{m}$.

SEM observations revealed that the external surface of conical papillae distributed on the root of tongue was smooth with somewhat broader bases (Fig. 5c). Though the external appearance of these conical papillae resembled that of filiform papillae, the CTCs of these conical papillae after removal of the epithelium exhibited a different morphological appearance. CTCs of conical papillae consisted from cone-like main CTCs and small protrusions were distributed especially from basal part of main cores (Fig. 5d). The length of the conical-shaped papillae was approximately 360 $-710 \mu \mathrm{m}$ and width was $220-390 \mu \mathrm{m}$.

\section{g) Lingual root}

Lightmicroscopy of the lingual root revealed a foldlike structure in this area (Fig. 1b: D). Large mucousrich mixed salivary glands were seen in the deep part of the lamina propria. Some ducts were observable and their orifices opened onto the epithelial surface.

After removal of epithelium, the surface of CTCs of this area had numerous folds and some ridge-like protrusions that were only visible in the SEM observations. The CTC surface of this area lacked interpapillary protrusions.

\section{Discussion}

Recent molecular-based phylogeny studies revealed that the Mustelidae family (weasels, badgers and otters) is categorized under infraorder Arctoidea (Fulton et al., 2006) that include Ursidae (Bears) and Procyonidae (Raccoons). Some molecular-based phylogeny studies also revealed a linkage between Mustelids and Pinnipedia (Fulton et al., 2006; Sato et al., 2006). 

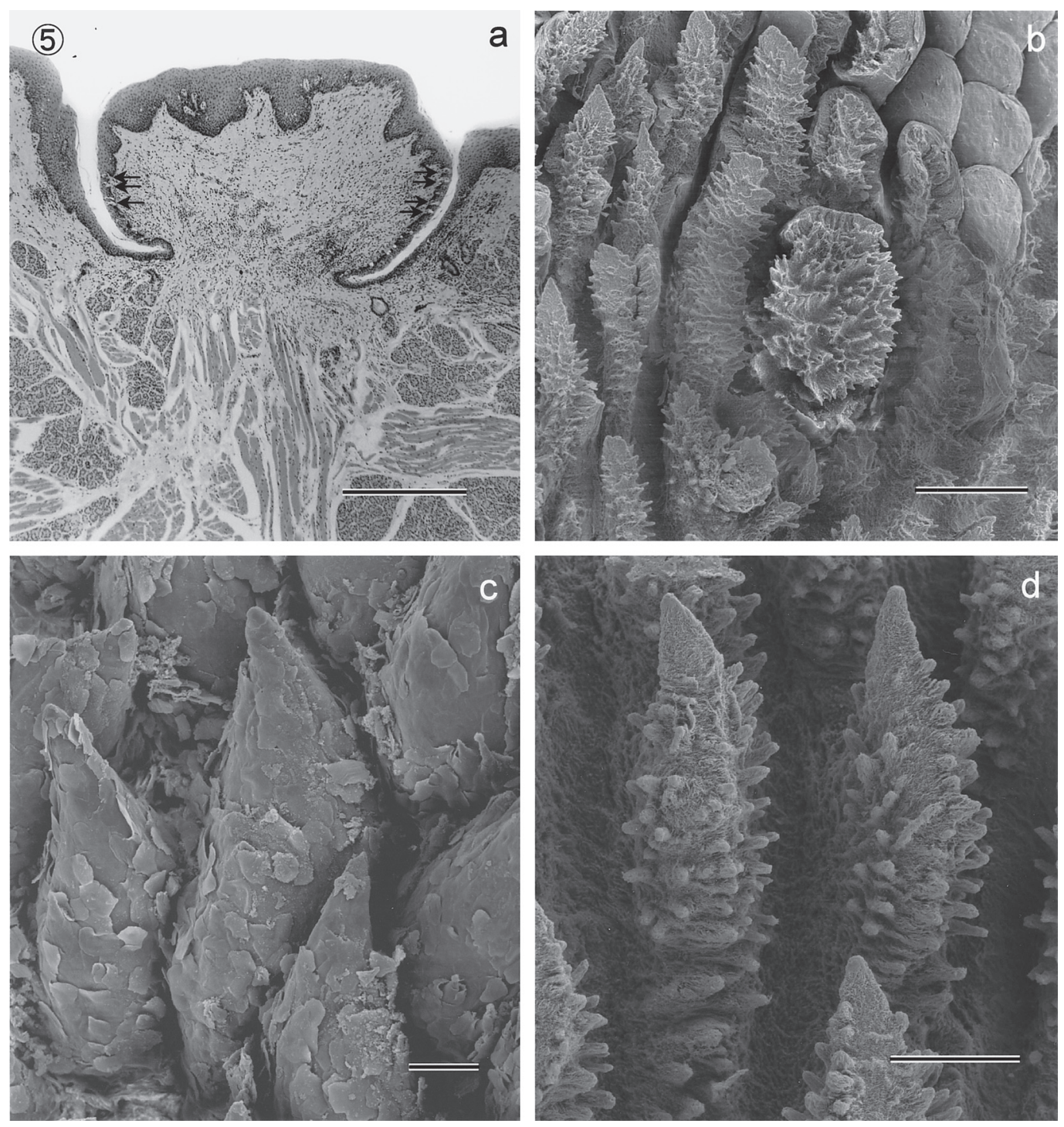

Fig. 5. A set of lingual papillae distributed on the posterior part (indicated as "C" on Fig. 1b) of the tongue. a: Lightmicrograph of a vallate papilla (sagittal section). Numerous taste buds (arrows) were found in the circumferential groove. Von Ebner glands were seen in the lamina propria. Scale bar $=500 \mu \mathrm{m}$. b: SEM micrograph of the partially exfoliated (left side) epithelium of a vallate papilla. Scale bar $=500 \mu \mathrm{m}$. c: SEM micrograph of the epithelial surface of conical papillae (indicated as "CP" on Fig. 1b). Scale bar $=100 \mu \mathrm{m}$. d: SEM micrograph of the CTCs of the conical papillae after removal of the epithelium. Cone-like main CTCs were seen. Small protrusions were distributed from main cores. Scale bar $=200 \mu \mathrm{m}$.

\section{Lingual papillae and their connective tissue cores}

The tongue of the Japanese badgers had each of the following lingual papillae: filiform, fungiform, conical, lateral organ and vallate papillae. Emura et al. (2007, 2008), reported lingual papillae of other Mustelid species i.e. ferret, Siberian weasel and Japanese Marten. The surface structure of filiform papillae of the ferret, Siberian weasel and Japanese weasel were quite similar to our observations in the Japanese badger. Surface structures of filiform papillae of these Mustelids consisted of a rather thick conical shaped protrusion and several acces- sory protrusions studded from the main protrusion. On the other hand, Shimoda et al. (1996), described the surface structure of the filiform papillae of the semi-aquatic Mustelid, Sea otter and noted that the surface structure of the filiform papillae of the Sea otter appeared to be conical shaped and lacked accessory protrusions. Smooth or lacking accessory protrusion on the filiform papillae has also been seen in the other aquatic Arctoidea, such as the California sea lion and Spotted seal (Yoshimura et al., 2002, 2007). These morphological differences may originate from not only their diets but also their living 

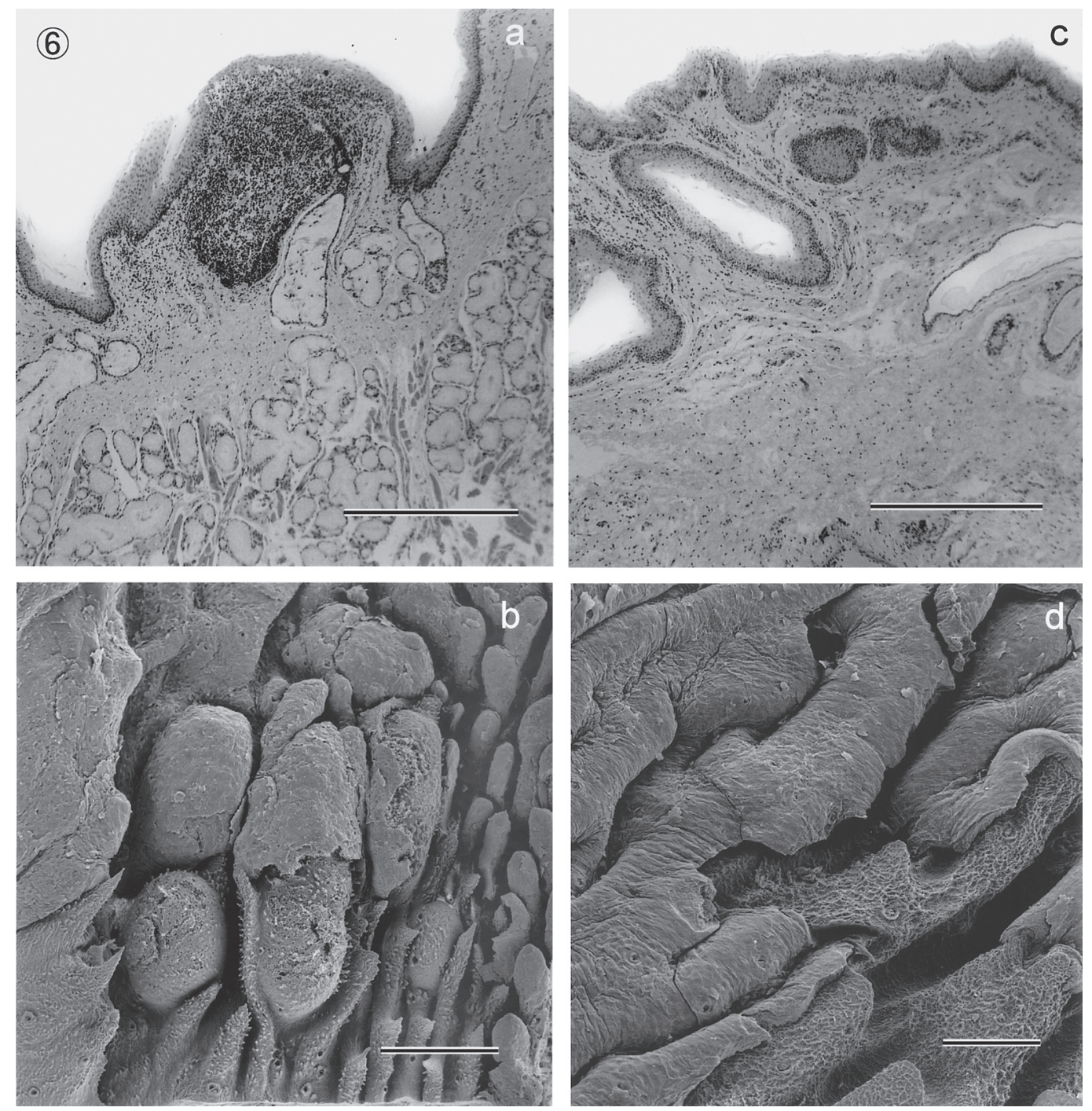

Fig. 6. A set of micrographs represented root of the tongue (shown as "D" on the Fig. 1b). a: Lightmicrograph of dome-like tonsils (indicated as "LT" on Fig. 1b) situated on the root area (sagittal section). Tonsillar follicle-like structure was observable on the superficial part of the lamina propria. Mucous-rich mixed salivary glands were situated in the deep part of the lamina propria. Scale bar $=500 \mu \mathrm{m}$. b: SEM micrograph of lingual tonsils partially removal (lower half) of the epithelium. Numerous dome-like tonsils were distributed in this area. Scale bar $=1000 \mu \mathrm{m}$. c: Lightmicrograph of posterior part of the root (sagittal section). Fold-like structure was seen. Scale bar $=300 \mu \mathrm{m}$. d: SEM micrograph of posterior part of root showing partial removal (lower right) of the epithelium. Surface of CTCs of this area lacked interpapillary protrusions. Scale bar $=500 \mu \mathrm{m}$.

environment, i.e. aquatic and terrestrial.

Regarding CTCs of filiform papillae of the Mustelid species; ferret, Siberian weasel and Japanese Marten (Emura et al., 2007, 2008), these exhibited similar threedimensional appearance with our present observations of the Japanese badger. CTCs of filiform papillae of these species exhibited a cylindrical stem and numerous small studded protrusions. Protrusions that were situated in the posterior part were rather increased in their size. Filiform CTCs were more elongated in the posterior part than in the middle of the tongue.
Filiform papillae of other carnivore species such as the cat and dog are well developed. The surface structure of the filiform papillae of cats and tigers consists of one long and sharp main protrusion which is hard (Kobayashi, 1988, 1992; review, Emura et al., 2004) and heavily cornified (Cat; Nickel et al., 1979). The surface structure of the filiform papillae of the Panda's tongue (Pastor et al., 2008 ) is elongated and has rather long accessory protrusions. In contrast, the surface structure of the filiform papillae of the Japanese Raccoon dog (Emura et al., 2006), Japanese black bear (Inatomi and Kobayashi, 1999) and 
Japanese badger did not appeared as elongated main protrusions with rather long accessory protrusions. Regarding the CTCs of the filiform papillae of the Japanese badger's tongue after removal of the epithelium, a main rod-like slender core was seen and short accessory protrusions ovally distributed around the main core. Inatomi and Kobayashi (1999) in their study of the filiform CTCs of the Japanese black bear reported that the basal part of each filiform CTC was cylindrical and a concavity was situated in the central part with ten or more small rodlike studs protruding upward. Among these cores, a main long protrusion was situated in the posterior part. Similar morphological characteristics are found also in other carnivores such as the cat and dog. CTCs of cat filiform papillae (Kobayashi et al., 1988) consist of one main protrusion and small circularly distributed protrusions. CTCs of dog filiform papillae exhibit a similar appearance that consist of one main protrusion and distribution of surrounding small protrusions in oval shape. The main CTC protrusion of the filiform papillae in both cat and dog tongues however incline posteriorly and the surrounding accessory protrusions are rather thick.

Though Japanese badgers are categorized as carnivores, the diet of Japanese badgers is omnivorous with main foods eaten: earthworms, insects (Yamamoto, 1991, 1994), and also fruits (Tanaka, 2005). The mixed dietary life is similar to some of other carnivore species such as raccoons and bears and morphological features especially the surface structure of filiform papillae may be representative of their masticatory method.

Yoshimura et al. (2002, 2007), observed the filiform CTCs of other aquatic Arctoidea, such as the Pinnipedia; California sea lion and Spotted seal. Filiform CTCs of the California sea lion appeared as thick conical shaped main processes, which were covered with numerous small rod-like secondary processes. Compared to the filiform CTCs of the California sea lion, filiform CTCs of the Spotted seal were somewhat similar to those of Japanese badger and consisted of a primary core associated with approximately 5-6 accessory processes distributed in a horseshoe shaped arrangement.

Regarding the fungiform papillae of the Japanese badgers, after removal of epithelium the CTCs exhibited a columnar-like shape. Regarding the CTCs of fungiform papillae of the Mustelid species: ferret, Siberian weasel and Japanese weasel (Emura et al., 2007, 2008) also exhibited similar morphology of lingual papillae and their CTCs. Fungiform CTCs of other Arctoidea species such as the Raccoon dog (Emura et al., 2006) exhibited a similar columnar appearance. Fungiform CTCs of the Japanese black bear (Inatomi and Kobayashi, 1999) however, appeared somewhat swollen and CTCs were spindle-like. Fungiform CTCs of the California sea lion (Yoshimura et al., 2002) were bulbous in appearance with numerous small rod-like secondary cores densely distributed on its surface. Fungiform CTCs of the Spotted seal appeared as a cylindrical primary core with numerous rod-shaped accessory protrusions.

In our present observation regarding the Japanese badgers' tongue, seven vallate papillae were arranged in a V-shape. According to reports of other Mustelids such as the Ferret and Japanese weasels (Emura, 2007, 2008) had four vallate papillae and the Siberian weasel (Emura, 2008) had six vallate papillae. Both species possessed a circumferential furrow. Sea otters (Shimoda et al., 1996) have eight vallate papillae with circumferential furrows. In other Arctoidea such as the White-nosed coati they possess eight vallate papillae (Sonntag, 1922) and the Japanese black bear (Inatomi and Kobayashi, 1999) have 7-10 vallate papillae.

Lateral organs are mainly found amongst carnivores. In the historical paper of Sonntag (1920) they defined a lateral organ that sometimes appeared instead of foliate papillae. Their appearance had some variations and some of them was lozenge-shaped, vermiform (similar to finger-like) or wedge-shaped and their margins serrated or plain. In the review of Kobayashi (1992) he described that three or so giant conical or finger-like lateral organs existed in the cat, dog and tree shrew where no taste buds could be found. In our observation of the Japanese badgers they exhibited a serrated lateral organ without taste buds that consisted of wedge-shaped protrusions. Other Mustelids, such as the Ferret and Siberian weasel have large-conical like papillae in place of foliate papillae (Emura, 2008). These are not serrated and somewhat different from our observation of Japanese badgers, however, they should be categorized as lateral organs. In the other hand, Mustelid species, Japanese Marten (Emura et al., 2007) had foliate papillae. Moreover, other carnivore species such as the Raccoon dog (Emura et al., 2006) and Japanese black bear (Inatomi and Kobayashi 1999) possess foliate papillae with numerous tastebuds. Japanese badgers, Japanese marten, raccoon dogs and Japanese black bears are categorized as carnivores and in infra order Arctoidea. Further investigations will be required regarding the diversity of foliate papillae and/or lateral organs among carnivorous species.

In our present observations regarding the Japanese badger's tongue, rather long conical papillae were distributed around vallate papillae. Though the surface appearance of these conical papillae was quite similar to those of filiform papillae, the CTCs after removal of epithelium exhibited a different morphological appearance. CTCs of conical papillae consisted of cone-like main CTCs with small protrusions especially from the basal part of main cores. Many carnivores possess conical papillae in the lingual root and their morphological appearance is distinguishable from those of filiform papillae. Shimoda et al. (1996), reported that triangular filiform papillae were distributed in the sea otter's lingual root. Yoshimura et al. (2002), also found spindle-shaped large conical papillae in the lingual root. After removal of epi- 
thelium, CTCs of conical papillae are covered with small rod-shaped protrusions of secondary cores. Inatomi and Kobayashi (1999) reported conical papillae distributed in the Japanese black bear's lingual root. The surface structure of conical papillae of Japanese black bears are thick and short and their CTCs are covered with small rod-like, ridge or mesh-like protrusions. In the aforementioned study, large conical papillae were found in the carnivorous cat and dog and seems to be one of the specific characteristics of carnivores.

\section{Lingual Tonsil}

Japanese badgers' tongues possess numerous domelike lingual tonsils that are densely distributed in a Ushaped arrangement behind the vallate papillae. Nickel et al. (1979), described that accumulations of lymphatic tissue are found in several places. Large numbers of lymph nodules combine with diffuse lymphatic tissue and form tonsils. There are two types of tonsils: those composed of tonsillar follicles and those that are not (nonfolicular tonsils). In our present observation, both globular tonsils and tonsillar follicles were found. According Nickel et al. (1979), no tonsillar follicles and only diffused lymphoid tissue and solitary nodules are seen in the carnivores tongue. Pigs were reported to have a few and ruminants had numerous tonsillar follicles in the tongue.

The structural similarity and/or differences compared with other carnivores implied that Japanese badgers might be situated in the transitional position among carnivorous species represented their dietary life and taxonomy position. Further studies including both morphological and molecular-based investigations should be needed.

\section{Acknowlegdements}

Drs. Zac Morse and Hiroyuki Yokosuka are gratefully acknowledged for their constructive criticism.

\section{References}

1) Emura $\mathrm{S}$, Hayakawa $\mathrm{D}$, Chen $\mathrm{H}$ and Shoumura S. Morphology of the lingual papillae in the tiger. Okajimas Folia Anat Jpn 2004; 81:39-44.

2) Emura S, Okumura $T$, Chen $H$ and Shoumura S. Morphology of the lingual papillae in the raccoon dog and fox. Okajimas Folia Anat Jpn 2006; 83:73-76.

3) Emura $S$, Okumura $T$ and Chen H. Morphology of the lingual papillae in the Japanese marten. Okajimas Folia Anat Jpn 2007; 84:77-81.

4) Emura $S$, Okumura $T$ and Chen H. SEM studies on the connective tissue cores of the lingual papillae of the Raccoon dog and
Masked palm civet. Struc Func 2008; 6:75-81.

5) Emura S. SEM studies of the lingual papillae and their connective tissue cores of the ferret and Siberian weasel. Med and Biol 2008; 2:48-56.

6) Fulton TL and Strobeck C. Molecular phylogeny of the Arctoidea (Carnivora): Effect of missing data on supertree and supermatrix analyses of multiple gene data sets. Mol Phylogenet Evol 2006; 41:165-181.

7) Inatomi $\mathrm{M}$ and Kobayashi K. Comparative Morphological Studies on the Tongue and Lingual Papillae of the Japanese black bear (Carnivora) and the Mountain goat (Artiodactyla). Odontology 1999; 87:313-328.

8) Inoue $\mathrm{T}$ and Osatake $\mathrm{H}$. A new drying method of biological specimens for scanning electron microscopy: The t-butyl alcohol freeze-drying method. Arch Histol Cytol 1988; 51:53-59.

9) Kobayashi K, Miyata K and Iwasaki S, Takahashi K Threedimensional structure of the connective tissue papillae of cat lingual papillae. Jpn J Oral Biol 1988; 30:719-731.

10) Kobayashi K and Iwasaki S. Comparative studies on the stereo architecture of the connective tissue papillae in some mammalian tongues. In: Motta PM, editor. Cell and Tissue: A Three-Dimensional Approach by Modern Techniques on Microscopy. Alan R. Liss, 1989; 303-308.

11) Kobayashi K. Comparative anatomical studies on the tongues with special reference to the connective tissue cores of the lingual papillae. Odontology 1992; 80:661-678.

12) Macdonald DW. In: Macdonald, D.W, ed. The Encyclopedia of Mammals. Facts on File Publications, 1984; 108-133.

13) Nickel R, Schummer A, Seiferle E. Digestive system. In: Schummer S, Nickel R $2^{\text {nd }}$ revised eds. The Viscera of the domestic mammals. Verlag Paul Parey, 1979; 23-62.

14) Pastor JF, Borbosa M and De Paz FJ. Morphological study of the lingual papillae of the giant panda (Ailuropoda melanoleuca) by scanning electron microscopy. J Anat 2008; 212:99-105.

15) Sato JJ, Mieczyslaw W, Suzuki H, Hosoda T, Yamaguchi Y, Hiyama K, Kobayashi M and Minami S. Evidence from nuclear DNA sequences sheds light on the phylogenetic relationship of Pinnipedia: Single origin with affinity to Musteloidea. Zoolog Sci 2006; 23:125-146.

16) Shimoda $T$, Nakanishi E, Yoshino $S$ and Kobayashi S. Light and scanning electron microscopic study on the lingual papillae in the newborn sea otter, Enhydra lutris. Okajimas Folia Anat Jpn 1996; 73:65-74.

17) Sonntag CF. The comparative anatomy of the tongues of the mammalian. I. General description of the tongue. Proc Zool Soc Lond 1920; IX:115-129.

18) Tanaka H. Seasonal and daily activity patterns of Japanese badgers (Meles meles anakuma) in western Honshu, Japan. Mammal study $2005 ; \mathbf{3 0 : 1 1 - 1 7}$

19) Yamamoto Y. Food habits of Meles meles anakuma in Mt. Nyuagasa, Nagano Pref., Japan. J Hiraoka Envir Sci Lab 1991; 4:73-83.

20) Yamamoto Y. Comparative analysis on food habits of Japanese marten, red fox, badger and raccoon dog in Mt. Nyuagasa, Nagano Pref., Japan. J Hiraoka Envir Sci Lab 1994; 7:44-52.

21) Yoshimura K, Shindoh J and Kobayashi K. Scanning electron microscopy study of the tongue and lingual papillae of the California sea lion (Zalophus californianus californianus). Anat Rec 2002; 267:146-153.

22) Yoshimura K, Shindo J, Miyawaki Y, Kobayashi K and Kageyama I. Scanning electron microscopic study on the tongue and lingual papillae of the adult spotted seal, Phoca largha. Okajimas Folia Anat Jpn 2007; 84:83-98. 